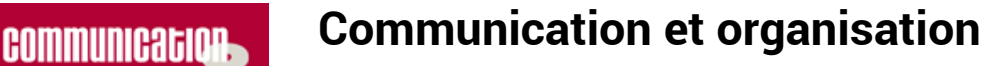

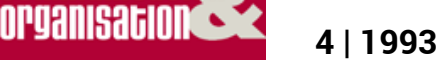

Les relations publiques face à la théorie

\title{
Chez Renault, des retraités historiens
}

\section{Hugues Hotier}

\section{OpenEdition}

Journals

Édition électronique

URL : http://journals.openedition.org/communicationorganisation/1683

DOI : 10.4000/communicationorganisation. 1683

ISSN : $1775-3546$

\section{Éditeur}

Presses universitaires de Bordeaux

Édition imprimée

Date de publication : 1 novembre 1993

ISSN : 1168-5549

\section{Référence électronique}

Hugues Hotier, "Chez Renault, des retraités historiens », Communication et organisation [En ligne], 4 I

1993, mis en ligne le 26 mars 2012, consulté le 10 décembre 2020. URL : http://

journals.openedition.org/communicationorganisation/1683 ; DOI : https://doi.org/10.4000/

communicationorganisation. 1683

Ce document a été généré automatiquement le 10 décembre 2020.

(c) Presses universitaires de Bordeaux 


\title{
Chez Renault, des retraités historiens
}

\author{
Hugues Hotier
}

1 Naguère Régie Nationale des Usines Renault, devenue récemment La Société Anonyme Renault SA, sur le point de fusionner, le 1er janvier 1994, avec le suédois Volvo pour former Renault-Volvo Automotive et être ainsi le sixième constructeur automobile mondial avec un effectif de 210.000 employés, la firme française cultive son histoire alors même qu'elle fêtera son centenaire en 1998.

2 Au 27 de la rue des Abondances, à Boulogne -Billancourt, en banlieue parisienne et à deux pas du berceau de la société, un très bel hôtel particulier construit à la fin du xix siècle abrite l'Expo-Musée-Renault. Ce magnifique immeuble est la propriété de l'Amicale du Groupe Renault, association regroupant des activités organisées à l'initiative du personnel et non de la direction. Dans le jardin qui entoure l'édifice, face à l'entrée du musée, une fresque figurative de six mètres de long illustre l'évolution de l'Usine de Billancourt de sa création en 1898 à la récente ère des robots qui précéda de peu la fermeture de 1992. Cette fresque est l'œuvre d'amateurs, des anciens de la Régie, retraités depuis plus ou moins longtemps. Tout ici, d'ailleurs est œuvre d'amateurs bénévoles, des retraités qui témoignent et préservent.

3 Cet amateurisme généreux est, par certains côtés, émouvant dans la mesure où il montre l'attachement à l'entreprise. Même s'il se concrétise parfois par des maladresses dans la présentation des documents qui sont souvent accumulés avec une densité que les règles les plus élémentaires de la muséographie condamnent.

4 La salle d'accueil comporte un comptoir où l'on peut se procurer revues, cartes postales, copies d'affiches et documents divers. On pénètre ensuite dans une enfilade de cinq salles thématiques. Chacune d'entre elles porte le nom d'une personnalité, connue ou oubliée, qui a marqué l'histoire de la Société d'une façon ou d'une autre. Pierre Lefaucheux, premier PDG de Renault après la nationalisation, dont le passé de résistant devait faire oublier que l'entreprise avait un peu flirté avec l'occupant durant la deuxième guerre mondiale, prête son nom à la salle consacrée à l'histoire de l'entreprise ; François Szisz, vainqueur en 1906, sur véhicule Renault bien entendu, du premier Grand Prix de l'Automobile Club de France a été choisi pour la salle dédiée à la compétition et aux 
randonnées africaines. La salle Louis Renault relate la vie et l'œuvre du fondateur, décédé en 1944. La salle Jean Guittard du nom d'un ancien chef du service des machines, propose à partir de photographies et de maquettes, une vision de l'évolution des moyens de fabrication. Le nom d'Eugène Blary, apprenti de 13 ans tué en 1917 dans l'effondrement d'un bâtiment, a été choisi pour la salle où sont évoquées les activités sociales, les associations, l'apprentissage mais aussi les mouvements sociaux. Des photographies et des journaux d'époque aident le visiteur à mieux comprendre la fonction symbolique que l'entreprise RENAULT a jouée au cours des cinquante dernières années et à se remémorer des expressions célèbres comme "ne pas désespérer Billancourt» ou "Renault, vitrine sociale de la France». Un vestibule présente des maquettes, des jouets et des objets publicitaires tandis que, à l'étage, la salle Marc Pampuzac, du nom d'un ancien chef de publicité, reçoit les visiteurs pour la diffusion de films vidéo ou pour des séances de questions-réponses. La création de ce musée est due à un ancien chef du personnel, Gilbert Hatry, décédé en 1992, féru de l'histoire de son entreprise au point d'avoir soutenu une thèse sur ce sujet.

6 Ayant accumulé de nombreux documents à l'occasion de sa recherche, il eut l'idée de les réunir, avec d'autres qui ne manqueraient pas de venir, en un lieu inauguré le 7 janvier 1988, Gilbert Hatry a laissé une trace considérable si l'on en juge par la déférence avec laquelle en parlent les responsables du musée. Il faut dire qu'ils n'étaient que quatre quand il s'est agi d'installer cette exposition et que l'intervention de l'entreprise fut des plus limitée. Peut-être parce qu'elle a elle-même un officiel Service Histoire et Patrimoine. Il n'en est que plus notable de constater l'effort de ces retraités pour perpétuer leur vision de la société. Là encore, l'adage est vérifié qui affirme que les employés de Renault ont un losange à la place du cœur.

7 Il ne faudrait surtout pas croire qu'il y a concurrence entre le service Histoire et Patrimoine de Renault S.A et la Société d'Histoire du Groupe Renault, fondée en 1969 sous le nom de "Section d'histoire des Usines Renault». A preuve la publication en commun d'une revue périodique, Renault Histoire.

Nous sommes ici en présence d'une initiative particulière, sinon privée, qui atteste de la persistance du sentiment d'appartenance chez les retraités. Il n'empêche que les responsables regrettent que leur musée, ouvert deux après-midi par semaine, ne soit visité que par des écoliers indifférents, des retraités nostalgiques ou des chercheurs passionnés, étrangers pour la plupart.

9 Peut-être faut-il conclure que les musées ne sont pas faits pour les acteurs en activité, si l'on ose cette redondance. Les responsables de la SNCF ne voient que le TGV et sont agacés quand on évoque, ému, les bonnes vieilles locomotives à vapeur. Le sixième constructeur automobile mondial ne peut se permettre de développer d'autre communication que prospective, même en interne. Il n'empêche que, pour les anciens, c'était toujours mieux avant. 